\title{
Yetersizliği Olan ve Olmayan Gençlerin Yetersizliğe Yönelik Tutumlarının Karşılaştırılması
}

\author{
Hatice Günayer S\$ENEL * \\ Aukara Universites!
}

$\mathbf{K}$

aynaştırma programlar ile birlikte yetersizlikleri olan bireyler, olabildiğince normal yaşıtlariyla birarada ve normal eğitim ortamında eğitim gormeye başlamışlardır. Kaynaştırma programlarının başanlı olması ise kaynaştırmanın yapıldığı ortamla ve bu ortamda yer alacak kişilerle ilgili bazı koșulların sağlanmasına bağhıdır. Bu koşullardan biri de bu programlarda yer alacak kişilerin yetersizliğe yonelik tutumlarıdır. Bu çalışmada da kaynaştırma ortamındaki en onemli grubu oluşturan, yetersizliği olan ve olmayan gençlerın yetersizliğe yonelik tutumlarına bakılmıştır. Bu amaçla oncelikle kaynaştırmanın ve yetersizliğe yonelik tutumların ne olduğuna değinilecektir. Turnbull ve Schultz'un (1979) tanımına gore kaynaştırma; normalden farklı çocukların, normal yaşıtları ile mumkun ulduğu olçude aynı ortamda eğitilebilmesıdir. Schulz, Carpenter ve Turnbull'a (1991) gore kaynaşturma terimi, Amerika'daki PL 94-142 Tum Ozurlu Çocuklar için Eğitim Yasası'nda onemle vurgulanan "en az kısıtlandırılmış ortam" terimi ile son derece benzerdir ve kaynaştırma, terim olarak bu yasa içinde yer almadı̆̆ halde kaynaştırma uygulamalarının bu yasa ile başladığı ca bilinmektedir. Buna gore, ozel eğitım gereksinimi olan oğrencilerin, okul gunlerinin en azından bir bolumunu normal sınıflarda ve normal yaşıtları ile ayn fiziksel, sosyal ve oğretim ortamlarında bir arada geçirebilmeleri kaynaştırma olarak tanımlanmaktadır.

Kaynaştırma programları, ulkemizde ise 2's16 saylı Ozel Eğitime Muhtaç Çocuklar Kanunu ile 1983 yılında yururluğe konulmuştur. Boylece özel eğitime muhtaç çocukların eğitimınin olabildiğince normal akranları arasında olması karara bağlanmıștır (Ozel Eğitimle Ilgili Mevzuat, 1991). Ancak giderek yaygınlaşan kaynaştırma programları beraberinde yanlış anlamaları ve uygulamaları da getirmiștir. Yetersizliği olan her bir çocuğun ne denli normal sınıf ortamında, ne denli ozel eğitim merkezlerinde veya bakım evlerinde bulunacağ; yetersizliğin derecesi, çocuğun kapasitesi, ihtiyaç duyulan eğitım

Yazışma Adresı: Ar Gor Hatıce Gunayer Senel, Ankara Universitesi, Eğutm Bulunlen Fakultesı, Ozel Eğıtım Bolumu 06590 Cebecl / ANKARA 
ortamları ve gereklı destek hızmetlerının goz onune alınması sonucunda kararlaştırılmalıdır Bu kararın da çocukla ılgıl kışılerden oluşan bır ekıp tarafindan alınması gerektığı de unutulmamalıdır (F1scus ve Mandel, 1983, Schullz ve ark , 1991) Kaynaştırma programlarmın etkılı bır şekılde uyguldnabılmesı ıçın oncelıkle nelerın goz onunde bulundurulması gerektığının ıyı bılınmesı gerekmektedır Bır kaynaştırma ortamı ıçın okulun ve sınıfin fizıksel yapısı, sınıf mevcudu, ders programları, gorev alacak kışlerın yetenek ve kapasıtelerı, araç-gereç donanımı kadar (Mac Millan ve Mormson, 1984), bu ortamda yer alacak kışılerın tutumlar ve bu tur programların uygulanmasina ne kadar hazır oldukları da değerlendırılmelıdır Yetersızlığı olan bıreylerın, normal yaşıtlaryyla olabıldığınce ayn ortamda eğıtım almalan goruşunun benımsenmesınde ve bu tur programların başarıl olabılmesınde, yetersızlığ olan kışlere yonelık olumlu tutumlar son derece onemlıdır (Johnson ve Johnson, 1984) Yetersızlığı olan kışımın yaşamında ve kaynaştırma programlarında, tutumlan onemlı olan kışler arasında, anne-babalar, kardeşler, arkadaşlar, ogretmenler, okul yonetıcılerı ve hatta yetersızlığ olan kışılerle ılgılı yasaları hazırlayanlar sayılabılır (Jones ve Guskın, 1984, Jamieson 1984)

Yetersızlığı olan bireylere yonelık tutumlar, bu kışılerın tum yaşamlarını etkıleyebılmektedır Şoyle kı, Telford (1973) fizıksel yetersızlığın tek başına bır ozure neden olamayacağm, ancak yetersızlığ olan kışının kendı kendısını ve başkalarnnın onu yetersız algılaması durumunda, yetersızlığın engele neden olacağını soylemıştır Nasıl kı çocukluk donemınde yetersızlığı olan kışlerın gehşını ve benlık kavramlaıı, yetersızlık durumundan, yetersızlığ alglamalarından ve annebabaların onlara yonehk tutumlarından etkllenmekte ıse çocuk buyudukçe arkadaşlarının ona yonelık goruş ve duşuncelen onem kazanmaktadır $\mathrm{Bu}$ konuyla ılghlı yapılmış olan araştırmalar da normal çocukların, fizıksel veya zıhınsel yetersızlığ olan yaşıtlarına yonelık olumlu tutumları olmadığını gostermıştır (MacMıllan ve ark, 1984) Popp ve Fu, yaptıkları araştırmada 4 ve 5 yaşındakı çocukların yetersızhğı olmayan yaşıtlanyla arkadaşlık etmeyı tercı ettıklermı saptamıştır, ote yandan Thompson, Parısh, Ohlsen ve Parısh okul çağındakı çocuklarda yetersızlığı olanların, sosyal ışbırlığıne daha az alındığını ve daha az tercıh edılır olduklarını saptamışlardır (Akt, Stukat, 1993) Ayrıca ılkokullarda oyun ve çalışma arkadası olarak, yetersızlığı olanlara oranla yetersızlığı olmayanların daha tercı edılır olduğu belırlenmış๋ır, buna bağh olarak da yetersızlığı olanlara yonelık reddedıcı tutumun, yetersızlığ olmayanlarda erken yaşlarda ortaya çıktığı sonu- 
cuna varılmıştır (Schullz ve ark., 1991). Higgs (1975) ise lise òğencileri arasından seçilmiş deneklerin, yetersizliği olanlarla daha az ilişkide bulunduklarnı ve onlara ilişkin daha az bilgiye ve daha az olumlu tutuma sahip olduklarını saptamıştır. Oysaki, fiziksel yetersizliklen olan kişiler ozel gereksinimlerine gore yapılandırılmış ortamlarda, yaşıtlarıyla birlikte eğitim gorme şansını elde ederken, kendilerine yonelik olumsuz tutumlardan da uzak olabilmelidirler. Olumsuz tutumlar arasında, yetersizliği olan bireylere acıma, onlardan uzak durma, arkadaş grubuna almama, yetersizliği alay konusu etme, kabul etmeme ve onları toplum dişında tutma isteği saylabilmektedir (Johnson ve ark., 1984).

Tum bu araştırma bulguları yetersizliği olan bireylerin, okuldaki arksadaşlarının, yaşıtlarının kendilerıne yonelik olumsuz tutumlanyla baş etmek zorunda oldukların gostermektedir. Yaşıtlarının, yetersizliği olan bireylere yonelik olumsuz tutumlar, bu bireyleri kaynaştırma progre mlannda başarısız kılabildiği gibi onları bır omur boyu mutsuz da edebilmektedir. Fiziksel gorunuşun ozellikle ergenlik doneminde ne denli onem kazandığ duşunulduğunde, fiziksel yetersızliğe sahip gençlerin bu donemlerinde yaşayacakları kaygının. normal yaşıtlarına oranla daha fazla olacağ duşunulebilinir. Eme, değişik kulturlerden gençlerde gozlenen ortak kayglardan birısinin, fiziksel gorunuşe verilen onem olduğunu saptamıştır (Akt., Şahin ve Şahin, 1995). Her ergenin yaşayacağ kayglara ek olarak, bir de fiziksel yetersizliğe sahip olmaktan oturu kendilerinin ve llışkide bulundukları diğer insanların onlara yonelik tutumlanyla baş etmelem gerekmektedir. Kendilernne yonelik bu olumsuz tutumların yam sıra onların yetersızlı ̧̌e yonelik tutumlarını, dolayısıyla kendilerıne yonelik tutumların 'ła araştımlması gereklidir. Bu gereklilikten ycla çıkılarak, bu araştırmada yetersizliğe sahip gençlerle, onların normal arkadaşlarının yetersizliğe yonelık tutumlan arasında fark olup olmadığ araştımlmaktadır. Ozellikle ergenlik doneminde, bireylerin benlik algısının nasıl kolayca değiştiği ve yaşıtların birbirinden ne denlı etkilendiği duşunulecek olursa, kaynaştırma ortamındaki normal gençlerin, yaşıtlanna yonelik tutumlarının onemi daha ıyi anlaşlacaktır. Tum bunların belirlenip daha olumlu hale donuşturulmesi, kaynaştırma ortamındaki bu gençleri daha mutlu ve başarılı kılacaktır.

\section{YÖNTEM}

\section{Araştırma Grubu}

Ankara ili sınırları içindeki 10 liseden, 15 yetersizliği olan genç ve bu gençlerle aynı sınıfa devam eden 15 normal genç araştırma grubunu 
oluşturmaktadır. Fiziksel yetersizliği olan gençler işitme, görme ve ortopedik yetersizliği olanlar arasından aynı sayıda seçilmiştir. Öncelikle okullardaki yetersizliği olan bu gençler belirlenmiş, ardından bu gençlerle aym sınıfa devam eden arkadaşlan tesadüfi yöntemle seçilerek "Yetersizlikten Etkilenmiş Kişilere Yönelik Tutum Ölçeği" uygulanmıştır. İşitme ve ortopedik yetersizliği olanlarla, normal gençler ölçeği kendileri okuyup doldururken, görme yetersizliği olan gençler ölçeği araştırmaca aracılığıyla doldurmuşlardır.

\section{Veri Toplama Arac1}

Liselerdeki normal ve yetersizliği olan gençlerin tutumlarını belirlemek amaciyla Yuker, Block ve Young (1970) tarafindan geliştirilen Yetersizlikten Etkilenmiş Kişilere Yönelik Tutum Ölçeği'nin $O$ formu uygulanmıştır. 20 maddeden oluşan bu ölçekten alınabilecek puanlar 0 ile 120 arasında değişmektedir. Ölçeğin amacı yetersizliği olan kişilere yönelik tutumu genel olarak ölçmektir. Ölçekten ahınacak göreceli düşük puanın, tepkide bulunan kişinin yetersizliği olanları, yetersizliği olmayanlardan farklı algıladığını gösterdiği, göreceli olarak yüksek bir puanın ise yetersizliği olan kişilerin fiziksel olarak yetersizliği olanlardan farklı algılanmadıkların gösterir olduğu belirtilmiştir (Lazar, Genseley ve Orpet, 1971). Ölçeğin Türkçe'ye Özyürek (1988) tarafindan uyarlanan $O$ formunun, test-tekrar test güvenirliği .76 bulunurken, ölçeğin kapsam geçerliği için de uzmanların görüşüne başvurulmuştur. Ölçeğin hem yetersizliği olan hem de yetersizliği olmayanların tutumlamnı araştırmada kullanılabileceği belirtilmiştir.

\section{Uygulama Süreci ve Verilerin Çözümlenmesi}

Ankara ili içerisindeki 10 devlet lisesi taranmış ve bu liselere devam eden, görme, işitme ve ortopedik yetersizlik durumlarndan birine sahip olan gençler belirlenmiştir. Her bir yetersizlik grubundan 5'er genç olmak üzere, çalışmaya katılmaya istekli toplam 15 kişiye ulaşılabilmiştir. Ardından yetersizliği olan bu gençlerle aynı sınıfa devam eden ve yetersizliği olmayan 15 genç de tesadüfi yöntemle belirlenmiştir. Her iki gruba ölçek uygulanmış ve her iki grubun yetersizliği olan kişilere yönelik tutumları arasında fark olup olmadığ t-test yoluyla sınanmıştır. Verilerin test edilmesinde .05 anlamlılık düzeyi benimsenmiştir. 


\section{SONUÇ}

$\mathrm{Bu}$ araştırmada yetersizliği olan ve olmayan gençlerin yetersizliği olan kişilere yönelik tutumları arasında fark olup olmadığı test edilmiştir. Yetersizliği olan ve olmayan gençlerin yetersizliğe yönelik tutumlarn arasındaki fark .05 düzeyinde anlamlı bulunmuştur $(t=2.44, p<.05)$ (Tablo 1).

Tablo 1 : Yetersizliği Olan ve Olmayan Gençlerin Tutum Puanlarmin Ortalamalart ve Standart Sapmalan

\begin{tabular}{|l|l|l|l|l|}
\hline Gruplar & N & X & ss & t \\
\hline $\begin{array}{l}\text { Yetersizliği Olan } \\
\begin{array}{l}\text { Yrup } \\
\text { Yetersizliği } \\
\text { Olmayan Grup }\end{array}\end{array}$ & 15 & 70.6 & 17.7 & \\
\hline
\end{tabular}

$P<.05$

\section{TARTIŞMA}

Araştırma grubundaki sayının azh̆ğ nedeni ile sonuçlar genelleme yapmaktan her ne kadar uzaksa da, bu konuyla ilgili yapılmış araştırma sonuçlarını destekler niteliktedir. Yetersizliği olan kişilerin, yetersizliği olmayan kişilere oranla daha olumlu tutuma sahip oldukları bulgusu, Yuker ve ark. (1970) ile Salend (1983)'in araştırma bulgularına benzerdir. Bu bulgu Popp ve ark., Thompson ve ark. (akt., Stukat, 1993) ve Higgs'in (1975) bulgularıyla da benzerlik göstermektedir. Şöyleki tüm bu araştırmalardaki bulgular değişik yaş gruplarından olan normal yaşıtların, yetersizliği olan yaşıtlarına yönelik olumsuz tutumlarını yansitmaktadır. Bu araştırma sonucunda da yetersizliği olmayan kişilerin yetersizliği olan kişilere yönelik daha olumsuz tutumlan olduğu saptanmıştır.

Yuker ve ark., (1970) ölçeği dolduran kişi eğer fiziksel yetersizliğe sahipse, aynı zamanda yetersizliği olan kişileri farklı algilıyorsa ve onları daha olumsuz görüyorsa, bu aslında ölçekteki maddeleri işaretlerken kendine yönelik tutumunun yansımasıdır demişlerdir. Bu yoruma göre ölçekten alınacak sonuç bir yerde yetersizliğe sahip kişilerin benlik kavramının bir yansıması olacaktır. Araştırmanın sonuçları bu yoruma göre değerlendirildiğinde, yetersizliği olmayanların, yetersizliğe sahip arkadaşlarını onların kendi kendilerini algladıklamndan daha olumsuz algladıkları anlamına gelebilir. Bu bilgilerin ıșığında yetersizliğe olan 
kişilerin kendi kendilerini algıladıklarından, daha olumsuz algılayan arkadaşlarıyla bir arada olmalarının kaynaştırma programlarının başarıya ulaşmasını guçleştirecektir.

Başarth bir kaynaştırma programunın varolması ancak bireysel farkhlıklarının kabul edilmesi ve saygı gormesiyle mumkundur. Aynı zamanda kaynaşturma programlanyla, yetersizliği olan olmayan yaşıtların, oğretimsel olduğu kadar sosyal yonden de bir arada olmalamna ve birlikte gelişmelerine firsat verilmelidir. Bu birliktelikte yetersizliğ olanlara yonelik tutumların, bu bireyleri psikolojik, sosyal ve akademik yonden etkilediğı gerçeği de goz onune ahımmalıdır. Normal oğrencilerin, fiziksel yetersizliği olan arkadaşlarına yardımcı olabildiklerini hissetmeleri, hem onların kendileri ile ilgili duşuncelerinde olumlu değişikliklere yol açacaktır, hem de yetersizliği olanlarla kuracakları ilişkıde onlara yonelik tutumlarına da olumlu katkıları olacaktır. Bu nedenle, her iki grup açısından etkili bir kaynaştırma ortamı sağlanabilmesi için yetersizliğe yonelik tutumun daha olumlu bir hale donuşturulmesi gereklidir. Oncelikle tutumun oluşmasında onemli rol oynayan değişkenler iyi bilınmelidir. Bu değişkenler arasında yetersizliği olan kişilerle kurulan ilişki ve onların hakkında kazanılmış bilginin rolu buyuktur. Salend (1983)'e gore yetersizliği olmayan oğrenciler, yetersizliği olan yaşıtlarına kar\$̧ hipotetik orneklerle daha fazla duyarlılık kazanabilir. $\mathrm{Bu}$ amaçla kaynaştırma ortamında hıpotetik ornekler oluşturmak için altı basamaklı bir model hazırlanmıştır. Ilk aşamada, oğrencinin guçlu ve zayıf yanları belirlenirken, aynı zamanda da guçluk çektiği alanların ve ozel gereksinimlerinin neler olduğu belirlenir. Ikincı aşamada ise çevresel koşulların netleştirilmesidir, bu adımda kaynaştırma ortamının ve sınıf yapısından kaynaklanan problemın analizı yapılır. Uçuncu aşamada ise birinci ve ikinci adımdaki bilgilerin karşılaştırılması yapılarak problem alanları belirlenir. Boylece normal sınıf ortamında ihtiyaç duyulanlarla, çocuğun ozel gereksinimleri arasındaki farklılık tesbit edilır. Dorduncu aşamada ise problem alanları hipotetik olarak belirlenir. Bunlarla problem alanının boyutları objektif olarak yansitılmalıdır. Beşinci aşamada ise kurulan bu hipotetik problemler sınıfa sunulur ve onlardan olası çozumleri durust ve olumlu olmaya çalışarak bulmaları istenir. Altıncı aşamada ise hıpotetik problemlere onerilen çozumlerden hangilerinin uygulanabilir ve işe yarar olduğunun değerlendirilmesi yapılır. Uzerinde uzlaşılan bir çozum bulunduğunda ıse bu aşama son bulur. Bu model, yetersizliği olmayan oğrencilere, yetersizliği olan arkadaşlanna gerektiği zaman ve nasıl yardım edeceklem oğretmede kullanılabilir. Boylece, hem yetersizliği olanların hem de olmayanlann birlikte olacakları okul yaşamına uymaları kolaylașır. 
Daha önceden yetersizliklerinden ötürü toplumdan soyutlanmış kişilerin, normallere tanınan eğitim firsatından yararlanmaları ve eşit haklara sahip olmaları ancak o toplumlarda ki değişen tutumla sağlanabilir. Yetersizliği olan ve olmayan bireylerin ayn ortamda tutulmalan her iki grubun yetersizliğe yönelik tutumlarını, düşüncelerini zaman içerisinde etkileyecektir. Yetersizliği olanlar, normal yaşıtlarının arasında yetersizlikleri ile nasıl baş edeceklerini öğrenirken, normal yaşıtlar ise bu arkadaşlarının bazı şeyleri kendileri gibi yapamadıklarını ancak aynı zamanda birçok şeyi ise aynen kendileri gibi yapabildiklerini fark edeceklerdir.

\section{KAYNAKÇA}

Fiscus, E.D., Mandel, C.J. (1983). Developing individualized educational programs. Minnesota: West Pub. Comp.

Higgs, R. W. (1975). Attitude formation-contact or information. Exceptional Children, 41, 496-497

Jamieson, J.D. (1984). Attitudes of educators toward the handicapped. Jones, R.L. (Ed.) Attitudes and attitude change in special education: Theory and practice, ERIC.

Johnson, D.W., Johnson, R.T. (1984). Classroom learning structure and attitudes toward handicapped students in mainstream settings: A theoretical model and research evidence. Attitudes and attitude change in special education: Theory and practice, ERIC.

Jones, R.L Guskin, S.L. (1984). Attitudes and attitude change in special education: Attitudes and attitude change in special education: Theory and practice, ERIC.

Lazar, A.L., Genseley, J.T., Orpet, R.T. (1971). Changing attitudes of young mentally gifted children toward handicapped persons. Exceptional Children, 37, 600-602.

Mac Millan, D.L., Morrison, G.M. (1984). Sociometric research in special education. Attitudes and attitude change in special education: Theory and practice, ERIC.

Özel eğitimle ilgili mevzuat, kanunlar, yönetmelikler, genelgeler, 1. Özel Eğitim Konseyi. (1991). Ankara: Milli Eğitim Basımevi. 
Özyürek, M. (1988). Engelli kişilere yönelik değiştirilen tutumların sürekliliği. Eskişehir: Anadolu Üniversitesi.

Salend, S. (1983). Using hypothetical examples to sensitize nonhandicapped students to their handicapped peers. The School Counselor, 30. 306-311.

Schulz, J.B., Carpenter, C.D., Turnbull, A.P. (1991). Mainstreaming exceptional students: a guide for calssroom teachers (3rd Ed.). Boston: Allyn and Bacon Inc.

Stukat, K.G. (1993). Integration of physically disabled sudents. European Journal of Special Needs Education, 8 (3), 249-268.

Şahin, N., Şahin, N. (1995). Dimensions of concerns; the case of Turkish adolescents. Journal of Adolescence, 18, 49-69.

Telford, W.C., Saures, M. J. (1973). The exceptional Individual psychology and educational aspects. London: Prentice Hall Inc.

Turnbull, A.P., Schulz, J.B. (1979). Mainstreaming handicapped students: a guide for elassroom teachers. Boston: Allyn and Bacon Inc.

Yuker, H. E., Block, J.R., Young, J.H. (1970). The measurement of attitudes towards disabled persons. New York: Institute at Human Resources Center. 